\title{
ORIGEM DOS TURMALINITOS AURÍFEROS DA REGIÃO SUDESTE DO QUADRILÁTERO FERRÍFERO-MG: GEOLOGIA, PETROGRAFIA, QUIIMICA MINERAL E ISÓTOPOS DE Nd
}

\author{
JOSÉ ADILSON DIAS CAVALCANTI ${ }^{1} \&$ ROBERTO PEREZ XAVIER ${ }^{2}$
}

\begin{abstract}
Resumo Os turmalinitos auríferos que ocorrem na região do Anticlinal de Mariana, sudeste do Quadrilátero Ferrífero, têm suscitado debates quanto à sua origem, podendo ser singenética e relacionada a focos exalativos ou epigenética e atribuída a processos metamórficos ou a magmatismo granítico. O estudo realizado nos depósitos auríferos de Passagem, Mata Cavalo, Scliar e Chico Rei mostrou que existem três modos de ocorrência da turmalina associada aos depósitos auríferos da região: (T1) turmalina em corpos de turmalinitos estratiformes; (T2) turmalina nos halos de alteração hidrotermal das encaixantes da mineralização; e (T3) turmalina em veios mineralizados. Apesar das diferenças composicionais, a turmalina foi classificada como dravita, pertencente ao grupo das turmalinas alcalinas. A correlação entre os dados de campo, petrografia, química mineral e os isótopos de Nd indicou que: i) a circulação profunda de fluidos gerou focos exalativos ricos em boro, que resultaram na precipitação do turmalinito estratiforme; ii) a formação da turmalina dos halos de turmalinização e dos veios mineralizados está relacionada com a mistura de fluidos mobilizados das rochas encaixantes e daqueles provenientes do sistema mineralizante.
\end{abstract}

Palavras-chave: depósito mineral, ouro, turmalina, Anticlinal de Mariana

Abstract ORIGIN OF THE AURIFEROUS TOURMALINITES IN THE SOUTHEASTERN QUADRILÁTERO FERRÍFERO (MG): EVIDENCE FROM FIELD, PETROGRAPHY, MINERAL CHEMISTRY AND Nd ISOTOPE DATA Auriferous tourmalinites of the Anticlinal de Mariana region, southeastern Quadrilátero Ferrífero, have long raised debates regarding their origin. Genetic models have considered the tourmalinites as syngenetic, invoking the importance of exhalative focus, as well as epigenetic formation as a result of hydrothermal alteration and/or granitic magmatism. This study was centred on the Passagem, Mata Cavalo, Scliar and Chico Rei gold deposits, where three distinct modes of tourmaline occurrences were identified: (T1) tourmaline as the essential component of stratiform tourmalinites; (T2) tourmalines concentrated as hydrothermal alteration envelopes around gold -bearing quartz-carbonate-sulphide veins; (T3) aggregates of tourmalines as part of gold -bearing quartz-carbonate-sulphide veins. In spite of their compositional differences, all belong to the group of alkaline tourmalines and are classified as dravite. Combining field relationships, together with petrography, mineral chemistry and $\mathrm{Nd}$ isotope data, the following conclusions regarding the origin of the gold-related tourmalinites may be pointed out: i) boron-rich submarine exhalative fluids caused the syngenetic precipitation of the stratiform bodies of tourmalinites; ii) remobilization of boron, possibly by metamorphic fluids sensu stricto derived from the metamorphic devolatilization of the enclosing rocks and deep-seated synmetamorphic fluids, may have caused the precipitation of vein-related tourmaline, as part of an epigenetic gold-bearing hydrothermal system.

Keywords: ore deposit, gold, tourmaline, Anticlinal de Mariana

INTRODUÇÃO A associação de turmalinito e turmalina com depósitos minerais, particularmente com depósitos auríferos, têm sido descrita em diversas províncias metalogenéticas pré-cambrianas, tais como a Província Superior (Canadá), Goldfield e Golden Dyke Dome (Austrália), Cráton Kaapvaal e Kéniéba (África do Sul). No Brasil é reconhecido um pequeno número de ocorrências de turmalinito na região centro-sul do país (Goiás, Minas Gerais, São Paulo, Santa Catarina e Rio Grande do Sul) que foram estudadas por Silva (1991) em terrenos arqueanos e proterozóicos. Na região sudeste do Quadrilátero Ferrífero-MG, particularmente no domínio do Anticlinal de Mariana, há presença significativa de rochas ricas em turmalina (turmalinito estratiforme, halos de alteração hidrotermal e veios ricos em turmalina) associadas a depósitos auríferos. Os corpos de turmalinito estratiforme dessa região ocorrem freqüentemente encaixados na base das formações ferríferas bandadas, em seqüências de rochas metassedimentares do Paleoproterozóico, pertencentes ao Supergrupo Minas. Alguns desses corpos de turmalinito encontram-se mineralizados a ouro, sendo normalmente utilizados como um dos guias de prospecção do ouro na região. Marcante também é a associação espacial desses corpos de turmalinito com os veios mineralizados. Há, também, turmalinito e turmalina em veios de quartzo que não possuem relação com a mineralização e se encontram encaixados nas rochas do Supergrupo Rio das Velhas (SGRV).

Nos diversos estudos realizados na região do Anticlinal de Mariana sobre as mineralizações auríferas, as ocorrências de turmalina associadas a estes depósitos foram interpretadas como resultantes de processos singenéticos (Fleischer \& Routhier 1973) ou resultante da alteração hidrotermal associada aos processos mineralizantes (Vial 1988). É evidente a relação espacial existente entre as rochas ricas em turmalina e os depósitos auríferos na região do Anticlinal de Mariana (Fleischer \& Routhier 1973, Barbosa et al. 1974, Heineck et al. 1986, Vial 1988, Duarte 1991, Ladeira 1991, Chauvet et al. 1994, Oliveira 1998, Cavalcanti 1999, Cavalcanti \& Schrank 1999, Chauvet et al. 2001). Entretanto, nenhum estudo foi realizado com maior profundidade sobre a origem desses turmalinitos e da turmalina, o que contribui para que haja controvérsias sobre a gênese dos depósitos auríferos da região. Devido à estreita associação espacial, o estudo dos turmalinitos e das turmalinas podem fornecer informações adicionais para futuros estudos sobre a gênese ou ambiente de formação desses depósitos.

Com o intuito de preencher esta lacuna, o principal objetivo deste estudo foi discutir a origem dos turmalinitos que ocorrem na região sudeste do Quadrilátero Ferrífero, particularmente na

1 - Prof. Visitante do Departamento de Geologia, UFC, jadcavalcanti@hotmail.com, Rua Osvaldo Cruz, 1000/2001, Aldeota, CEP: 60.125-150, Fortaleza-CE 2 - Prof. Associado do Instituto de Geociências, Unicamp, xavier@ige.unicamp.br, Rua João Pandiá Calógeras, 51, Cidade Universitária Zeferino Vaz, Barão Geraldo, CEP: 13.083-870, Campinas-SP 
região do Anticlinal de Mariana, onde se encontram associados a importantes mineralizações auríferas. Para alcançar tal propósito, este trabalho concentrou-se na caracterização dos tipos de turmalina associadas a vários depósitos auríferos do Anticlinal de Mariana, com base em relações de campo, petrografia, química mineral e da geoquímica isotópica $\mathrm{Nd}$.

CONTEXTO GEOLÓGICO O Quadrilátero Ferrífero (QF) é uma das principais províncias metalogenéticas do Brasil. Os depósitos auríferos mais conhecidos da região são: Morro Velho, Cuiabá, Raposos, São Bento e Passagem de Mariana. A região do Anticlinal de Mariana, no sudeste do Quadrilátero Ferrífero, é de grande interesse científico e também bastante conhecido por sua produção aurífera histórica de, aproximadamente, 350 toneladas de ouro (Lanari 1977), a qual remonta ao período colonial. O QF localiza-se no extremo sul do Cráton São Francisco e corresponde a uma porção da crosta estabilizada desde o Neoproterozóico, sendo que no Arqueano fazia parte de um bloco mais extenso denominado Cráton Paramirim (Almeida 1977, 1981). A região é balizada por dois grandes eventos tectono-metamórficos, o Transamazônico e o Brasiliano. No entanto, a partir das análises do acervo de dados geocronológicos disponíveis, Endo \& Machado (2002) caracterizaram os seguintes ciclos geodinâmicos no QF e adjacências: i) Ciclo Rio das Velhas (2920 Ma a $2555 \mathrm{Ma}$ ); ii) Ciclo Transamazônico (2250 Ma a $1900 \mathrm{Ma}$ ); iii) Ciclo Espinhaço (1770 Ma a ?); e iv) Ciclo Brasiliano (600 Ma a $450 \mathrm{Ma}$ ). As unidades lito-estratigráficas que compõem a região estudada são representadas pelos supergrupos Rio das Velhas (SGRV) e Minas (SGM) (Fig.1 e Fig.2).

Estudos anteriores têm demonstrado a dificuldade de se identificar, em alguns pontos ao longo do anticlinal, as unidades estratigráficas envolvidas com a mineralização, podendo as mesmas pertencer tanto ao SGM quanto ao SGRV, ou o minério está posicionado na zona de contato entre as duas unidades (Vial 1988, Duarte 1991, Oliveira 1998, Chauvet et al. 1994). Isto ocorre, por exemplo, na Mina da Passagem, onde os corpos de minério associam-se a um complexo imbricado de rochas alteradas hidrotermalmente durante eventos metamórficos que afetaram a região. No contexto regional, tem-se afirmado que a lapa do minério é constituída de quartzo-sericita xistos interpretados como pertencentes ao SGRV ou quartzitos sericíticos pertencentes ao SGM, ao passo que a capa é composta de itabiritos do SGM e que o

\begin{tabular}{|c|c|c|c|c|c|}
\hline Idade & Supergrupo & Grupo & Formação & Litologia & Esp.Max.(m) \\
\hline \multirow{10}{*}{ 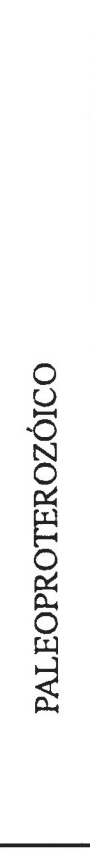 } & \multirow{10}{*}{ 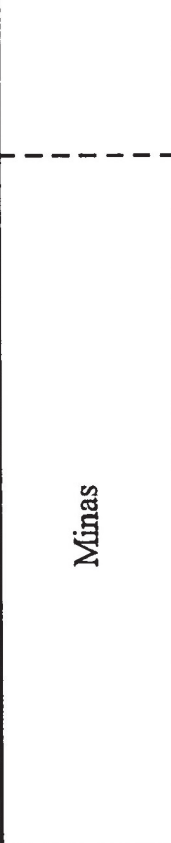 } & 롱 & Indiviso & $\begin{array}{l}\text { ortoquartzitos, quartzitos (matriz ferruginosa), filitos quartzosos, } \\
\text { filitos e conglomerados com seixos de itabiritos }\end{array}$ & $>1000$ \\
\hline & & Sabará & Indiviso & 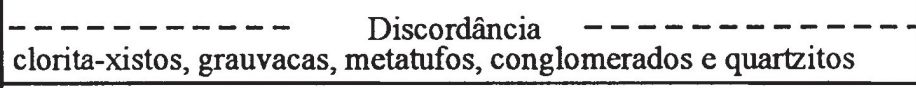 & $-\frac{----}{>3000}$ \\
\hline & & \multirow{4}{*}{ 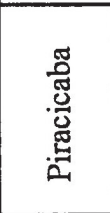 } & Barreiro & filitos e filitos grafitosos & 150 \\
\hline & & & Taboões & ortoquartzitos & 125 \\
\hline & & & Fecho do Funil & filitos, filitos dolomíticos e dolomito silicoso & 410 \\
\hline & & & Cercadinho & quartzitos ferruginosos, quartzitos, filitos ferruginosos e dolomitos & 600 \\
\hline & & \multirow{2}{*}{ 䀅 } & Gandarela & dolomitos, filitos dolomiticos e calcários & 600 \\
\hline & & & Cauê & itabiritos, itabiritos dolomiticos e hematíticos & 350 \\
\hline & & \multirow{2}{*}{ 胥 } & Batatal & filitos e filitos grafitosos & 500 \\
\hline & & & Moeda & $\begin{array}{l}\text { quartzitos sericíticos, conglomerados e filitos } \\
-\end{array}$ & 1000 \\
\hline \multirow{4}{*}{ 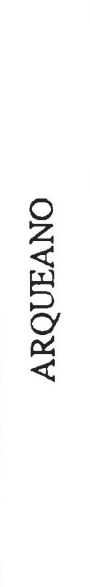 } & \multirow{4}{*}{ 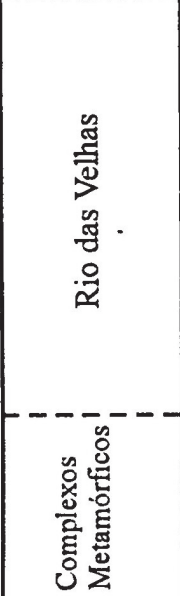 } & 莺 & Indiviso & quartzitos, conglomerados, sericita-quartzo-xistos e filitos & \\
\hline & & 之. & Indiviso & $\begin{array}{l}\text { filitos cloriticos, filitos grafitosos, metagrauvacas, formações } \\
\text { ferriferas, quartzitos, metacherts, dolomitos, rochas máficas } \\
\text { e ultramáficas }\end{array}$ & $>4000$ \\
\hline & & 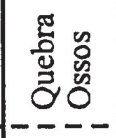 & Indiviso & $\begin{array}{l}\text { komatiitos, formações ferriferas e metacherts } \\
\end{array}$ & $>600$ \\
\hline & & : & Indiviso & gnaisses bandados, gnaisses migmatíticos, augen-gnaisses e granitos & \\
\hline
\end{tabular}

Figura 1 - Coluna lito-estratigráfica para a região do Quadrilátero Ferrifero (compilada e adaptada de Endo 1997). 
minério também está contido nestas unidades (Vial 1988).

De acordo com Oliveira (1998), a seqüência litológica envolvida na mineralização da Mina da Passagem é a seguinte, da base para o topo: quartzitos, filitos e xistos carbonáceos, turmalinitos, mármores, metacherts, rocha quartzo-carbonáticas, muscovita-biotita xistos e itabiritos. Na Mina Mata Cavalo, Heineck et al. (1986) apresentaram as encaixantes do minério como sendo biotita xistos e sericita-quartzo xistos do SGRV; quartzo xistos e quartzitos da Formação Moeda, além de itabiritos da Formação Cauê. No Palácio Velho, Cavalcanti (1999) apresenta as seguintes encaixantes para o minério: quartzo-sericita xistos (lapa) pertencentes ao SGRV, quartzitos sericíticos da Formação Moeda, filitos e xistos carbonáceos da Formação Batatal e formações ferríferas bandadas da Formação Cauê. Já Chauvet et al. (1994), propõem que a mineralização ocorreu na zona de contato entre o SGRV (base) e o SGM (topo). Neste estudo ficou evidenciado que a mineralização aurífera ocorreu tanto nas rochas do SGRV, quanto nas rochas do SGM.

\section{TURMALINITOS}

Apresentação e conceitos Os turmalinitos são unidades litológicas estratiformes, concordantes com as rochas hospedeiras, contendo mais de $20 \%$ em volume de turmalina (Slack et al. 1984). Essas rochas mantêm perfeita concordância com terrenos polideformados e podem ser traçadas continuamente como uma unidade litoestratigráfica. Outra expressão muito utilizada na literatura é "rochas ricas em turmalina" (tourmaline-rich rocks), sendo geralmente atribuída às rochas que não são estratiformes e que se encontram associadas a pegmatitos, veios me- tamórficos e halos de turmalinização. Há controvérsias quanto ao uso do termo turmalinito, que no Brasil chegou a ser chamado de "carvoeira" (Ladeira 1991). Em algumas publicações, os termos "turmalinitos" e "rochas ricas em turmalina" têm sido usados como sinônimos, não os relacionando com a geometria ou com a gênese.

Estudos recentes têm demonstrado que os turmalinitos estão presentes em muitos terrenos metassedimentares e metavulcânicos de idades que se estendem desde o Aqueano até o Permiano, além de associar-se a importantes depósitos minerais de $\mathrm{Pb}, \mathrm{Zn}$, $\mathrm{Ag}, \mathrm{Sn}, \mathrm{Au}$ e outros, em várias províncias minerais espalhadas pelo globo (Fleischer \& Routhier 1973, Ethier \& Campbell 1977, Taylor \& Slack 1984, Plimer 1986, Vial 1988, Clarke et al. 1989, Byerly \& Palmer 1991, Dommanget et al. 1993, Slack et al. 1993, Jiang et al. 1995, London \& Manning 1995, Steven \& Moore 1995, Cleland et al. 1996, Garba 1996, Griffin \& Slack 1996, Slack 1996, Pesquera \& Velasco 1997, Bone 1998, Cavalcanti \& Schrank 1999, Jiang et al. 1999, Lerouge et al. 1999, Harraz \& Sharkawy 2001, Torres-Ruiz et al. 2003).

Os turmalinitos são compostos, principalmente, por turmalina e quartzo, mas podem conter quantidades apreciáveis de feldspatos, muscovita, biotita, clorita, flogopita, stilpnomelana, granada, apatita, rutilo, sulfetos, Fe-dolomita, grafita, e material carbonáceo (Slack et al. 1984, Plimer 1986, Garba 1996, Pesquera \& Velasco 1997, Harraz \& Sharkawy 2001). O metamorfismo pode provocar o desenvolvimento de granulação mais grossa na turmalina, gerando zoneamento composicional e até mesmo remobilizá-la, o que é relativamente comum em terrenos altamente deformados (Plimer 1986). Estudos recentes

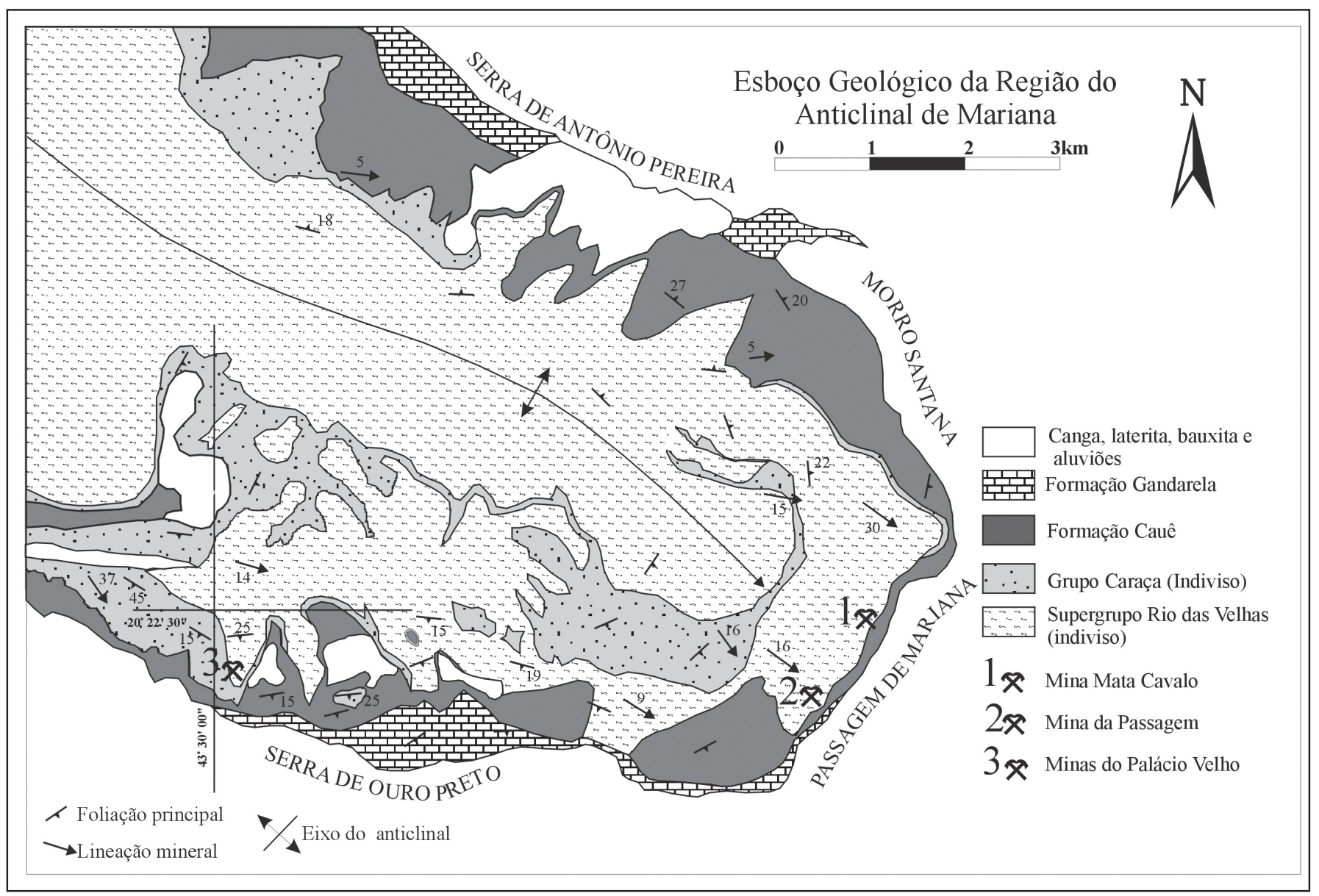

Figura 2 - Mapa geológico simplificado da região do Anticlinal de Mariana com localização da área estuda (modificado de Barbosa 1969). 
têm mostrado que a turmalina pode ser substituída durante eventos hidrotermais e metamórficos, como no depósito de Sullivan, onde localmente a turmalina foi substituída por clorita, muscovita e/ou albita durante atividade hidrotermal (Slack 1996).

Existem muitas controvérsias quanto à origem dos turmalinitos, mas a maioria dos estudos tem atribuído sua origem a processos pré-metamórficos, normalmente relacionada a sistemas hidrotermais submarinos ou evaporíticos (Pesquera \& Velasco 1997). Entretanto, diferentes modelos têm sido discutidos, tais como: substituição pré-metamórfica, exalativo singenético, soluções coloidais, evaporítico, metassomatismo de contato e regional.

A origem pré-metamórfica é atribuída à substituição dos sedimentos ou rochas vulcânicas aluminosas a partir de sua reação com fluidos ricos em boro.

Dados de campo e geoquímicos têm demonstrado que os turmalinitos podem ter sua origem relacionada a processos exalativos singenéticos e a maior evidência desse processo é a ocorrência de turmalinitos em contato direto com depósitos de sulfetos estratiformes e formações ferríferas (Ethier \& Campbell 1977, Slack 1996, Slack et al. 1984, Plimer 1986). Nesse modelo, o boro é concentrado no assoalho oceânico a partir de focos exalativos salinos quentes que reagem com sedimentos aluminosos para formar turmalina ou um mineral precursor. A formação desses turmalinitos pode ocorrer por meio da lixiviação hidrotermal submarina profunda de boro (Slack 1982, Plimer 1986, Palmer \& Slack 1989). O boro é lixiviado de sedimentos marinhos, rochas vulcânicas félsicas ou evaporitos e transportado em fluidos hidrotermais na forma de moléculas de $\mathrm{B}(\mathrm{OH})_{3}$, precipitando-se como turmalina, ou um mineral precursor, próximo ou na interface sedimento-água (Slack 1996).

Em ambientes evaporíticos, a turmalina provavelmente forma-se através de fases precursoras. Modelos envolvendo diagênese de boratos in situ podem ser descartados, pois estes são altamente solúveis, inibindo assim a produção de turmalinas. Precursores de turmalinas nesses ambientes são misturas de silicatos ferro-magnesianos, clorita e borossilicatos de $\mathrm{Na}+\mathrm{Ca}$ (redmergerita e siarlesita), abundantes em depósitos evaporíticos lacustrinos. A formação de turmalina a partir de um mineral precursor ocorre durante a diagênese. Reações em subsuperfície de fluidos ricos em boro com ilita/smectita + clorita podem resultar na precipitação de grandes quantidades de turmalina (Slack et al. 1984).

O metassomatismo de contato, próximo às intrusões de granitóides, pode gerar turmalinitos (Black 1971, London et al. 1996). Nesse tipo de ambiente, os turmalinitos formam-se, principalmente, por metassomatismo de rochas pelíticas aluminosas. Em alguns casos, somente o boro é introduzido (Kretz et al. 1989); em outros, o metassomatismo introduz $\mathrm{Si}, \mathrm{Fe}, \mathrm{Mg}, \mathrm{Al}$, $\mathrm{Ca}$, enquanto o $\mathrm{P}, \mathrm{Na}, \mathrm{K}, \mathrm{Ba}$, $\mathrm{Sr}$ e o Rb são comumente removidos (Black 1971, Shearer et al. 1984, Kretz et al. 1989).

Concentrações de turmalina em terrenos metamórficos de alto grau são raras, isto porque o boro geralmente fica retido em sedimentos clásticos e outras rochas durante o metamorfismo da fácies anfibolito a granulito (Henry \& Dutrow 1998, Leeman et al. 1992). No distrito de Broken Hill, por exemplo, turmalinitos discordantes formaram-se por remobilização de turmalinitos estratiformes pré-metamórficos durante deformação e metamorfismo (Slack et al. 1993).

No presente estudo, a expressão "rochas ricas em turmalina" é utilizada para descrever as diversas associações da turmalina, sejam os turmalinitos, os halos de turmalinização ou os veios ricos em turmalina. O termo "turmalinito" é aplicado para descrever as rochas compostas principalmente por turmalina $(>60 \%)$, que ocorrem como corpos estratiformes e também na forma de camadas de espessuras centimétricas contínuas nas unidades litológicas. O termo "turmalinização" é usado para descrever os halos de alteração hidrotermal nas encaixantes em torno dos veios. Já para os veios que contêm turmalina, será utilizada a expressão "veios ricos em turmalina".

Associação de turmalinitos com depósitos auríferos A turmalina é um mineral de ganga encontrado em muitos tipos de depósitos minerais que contêm ouro, prata, tungstênio, cobre, estanho, chumbo, zinco, cobalto e urânio (Fleischer \& Routhier 1973, Ethier \& Campbell, 1977, Slack et al. 1984, Taylor \& Slack 1984, Plimer 1986, Cavarretta \& Puxeddu 1990, Dommanget et al. 1993, Slack et al. 1993, Jiang et al. 1995, Cleland et al. 1996, Garba 1996, Griffin et al. 1996, Bone 1998). As concentrações de turmalina associadas a depósitos estratiformes, na maioria dos casos, representam o resultado de alterações hidrotermais locais (Slack 1996). Em depósitos filonianos hospedados em terrenos metamórficos, a turmalina representa o produto da alteração hidrotermal das rochas encaixantes ou é o resultado da precipitação direta de fluidos hidrotermais. Exemplos da associação de turmalinitos com depósitos auríferos ocorrem em: Golden Dyke Dome, Austrália (Plimer 1986); Província Goldfields Oriental, nos terrenos de Norseman da Austrália Ocidental (Groves et al. 1989); Sigma Mine, na Província Superior do Canadá (Jebrak et al. 1990); Kolar Goldfields da Índia (Siva Siddaiah \& Rajamani 1992); Cráton Kaapvaal da África do Sul (Foster \& Piper 1993); Loulo Gold, oeste da África (Dommanget et al. 1993); Bin Yauri, na Nigéria (Garba 1996); Dorlin, na Guiana Francesa (Lerouge et al. 1999); Big Bell e Mount Gibson, em Yilgarn, na Austrália (Jiang et al. 2002). Os turmalinitos auríferos de Golden Dyke Dome e Bin Yauri são considerados similares aos descritos em Passagem de Mariana (Plimer 1996, Garba 1996).

Os turmalinitos ocorrem em cinco posições estratigráficas distintas nos terrenos metassedimentares e metavulcânicos do Paleoproterozóico em Golden Dyke Dome (Austrália), estando hospedados em rochas metassedimentares pelíticas carbonáceas e associados a outros exalitos (Plimer 1986). O ambiente geológico, as associações com exalitos, as estruturas sedimentares e a composição química dos turmalinitos excluem sua origem por meio dos fluidos derivados da cristalização de granitos. Plimer (1986) concluiu que esses turmalinitos precipitaram-se a partir de fluidos exalativos submarinos e ainda propôs similaridades entre o depósito aurífero de Golden Dyke Dome e o depósito de Passagem de Mariana, com base nas interpretações de Fleischer \& Routhier (1973).

Em Bin Yauri (Nigéria), a mineralização aurífera também possui estreita relação com turmalinitos e turmalinas, que ocorrem em três tipos distintos: i) turmalinito estratiforme confinado em rochas sedimentares pelíticas, ii) turmalina em assembléias de alteração hidrotermal nas encaixantes, e iii) turmalina em veios auríferos de quartzo e quartzo-carbonatos (Garba 1994). Este autor concluiu que existem pelo menos dois estágios de formação de turmalina: o primeiro envolvendo a formação de turmalinito singenético-diagenético e o segundo, de natureza epigenética, possivelmente derivado da desidratação e da devolatilização de seqüências metassedimentares que contêm turmalinito.

No depósito de Loulo Gold (oeste da África), o processo de mineralização aurífera foi restrito a zonas turmalinizadas e mostra várias feições que são comuns em outros depósitos minerais de origem submarino-exalativa, como demonstrou Slack (1982). Este depósito apresenta concentrações de turmalina em pipes e camadas estratiformes (Dommanget et al. 1993).

$\mathrm{Na}$ área de estudo, os turmalinitos ocorrem associados aos vários depósitos auríferos localizados no flanco sul do Anticlinal de Mariana. Na região do Anticlinal de Mariana, os turmalinitos estratiformes possuem grande extensão lateral e constituem um dos minérios. As turmalinas, além de constituírem 
turmalinitos estratiformes, encontram-se também associadas aos halos de alteração hidrotermal hospedados nas rochas encaixantes da mineralização, e na forma de agregados maciços nos veios mineralizados. Um outro modo de ocorrência dos turmalinitos é sob a forma de brechas que se encontram associadas aos veios mineralizados.

MATERIAIS E MÉTODOS A primeira fase da pesquisa foi direcionada para estudos da geologia das rochas ricas em turmalina com o objetivo de localizar e estabelecer parâmetros descritivos tais como a geometria, as estruturas e o contexto lito-estratigráfico, além de definir (ou classificar) os principais modos de ocorrência da turmalina e do turmalinito nos diversos pontos estudados.

As amostras usadas nos estudos petrográficos foram selecionadas a partir da descrição macroscópica de um conjunto maior. A petrografia foi realizada em microscópio ótico utilizando luz transmitida e refletida em 120 lâminas delgadas-polidas de rochas encaixantes, turmalinito, halos de alteração hidrotermal e veios mineralizados. Estes estudos propiciaram a caracterização dos modos de ocorrência das turmalinas, definindo a sua composição mineralógica, texturas e estruturas. Possibilitou, além disso, estabelecer as principais características da associação turmalina e turmalinito com a matéria carbonácea e a mineralização aurífera.

A partir dos trabalhos de campo e das análises petrográficas, foram definidos os modos de ocorrência das turmalinas, suas associações e relações com as encaixantes, hospedeiras e mineralização aurífera. Com base nestes critérios, foram selecionadas 10 seções delgadas-polidas de turmalinitos, halos de turmalinização e veios com turmalina para as análises utilizando a microssonda eletrônica. Nestas seções foram realizadas 129 análises pontuais nas turmalinas; em alguns casos foram analisadas as mudanças composicionais que poderiam ocorrer no zoneamento de cor observado no microscópio ótico. Esse método teve como objetivo principal determinar a composição química das turmalinas. Foi utilizada a Microssonda CAMECA SX50, do Laboratório de Microssonda Eletrônica do Centro de Estudos em Petrologia e Geoquímica do Instituto de Geociências, da Universidade Federal do Rio Grande do Sul. As condições de operação foram: 15 $\mathrm{KeV}$ de voltagem, $10 \mathrm{nA}$ de corrente, $1 \mu \mathrm{m}$ o diâmetro do feixe eletrônico e 30 segundos de contagem. As análises foram feitas por WDS utilizando como padrões analíticos minerais e compostos sintéticos: ${ }^{-1} \mathrm{~F}\left(\right.$ caf2) - fluorita; ${ }^{2} \mathrm{Mg}(\mathrm{MnHo})$ - Mn-olivina; ${ }^{3} \mathrm{Al}$ (anor) - anortita; 4Ti(TiO) - rutilo; ${ }^{2} \mathrm{Fe}(\mathrm{MnHO})$ - Mn-olivina; ${ }^{2} \mathrm{Ni}(\mathrm{NiO})$ - óxido de níquel; ${ }^{-1} \mathrm{Cl}(\mathrm{Clap})$ - cloro-apatita; ${ }^{1} \mathrm{~K}$ (asbe) - microclínio; ${ }^{2} \mathrm{Ca}$ (anor) - anortita sintética; ${ }^{3} \mathrm{Cr}\left(\mathrm{Cr}_{2} \mathrm{O}_{3}\right)$ - óxido de cromo; ${ }^{2} \mathrm{Mn}(\mathrm{MnHO}) ;{ }^{1} \mathrm{Na}$ (Jade) - jadeíta; $\mathrm{Si}$ (anor) - anortita sintética; e efeito de correção PAP (Potts et al. 1995). Para o tratamento dos dados, foram utilizados os seguintes softwares: TOURMAL (Yavuz 1997) para o cálculo das proporções moleculares entre Al-Fe-Mg e Ca-Fe-Mg; CLASSTOUR (Yavuz et al. 2002) para a classificação dos minerais do grupo da turmalina; e ORIGIN 6.1 para a elaboração final dos gráficos.

As análises isotópicas de $\mathrm{Sm}-\mathrm{Nd}$ tiveram como o objetivo de aprofundar as discussões sobre as possíveis fontes de fluidos ricos em boro que contribuíram para a formação das turmalinas do turmalinito, dos halos de alteração hidrotermal e dos veios mineralizados. Foram selecionadas nove amostras para as análises de $\mathrm{Sm}-\mathrm{Nd}$, obtidas a partir dos concentrados de turmalina dos turmalinitos, das encaixantes e dos veios mineralizados. O método utilizado foi o descrito por Gioia \& Pimentel (2000). Cerca de $50 \mathrm{mg}$ de turmalina foram misturados a uma solução spike e dissolvidas em cápsulas Savillex em bombas Teflon. A extração de $\mathrm{Sm}$ e Nd foram feitas em colunas contendo resina LN-Spec. As amostras para Sm-Nd foram analisadas no espectrômetro de massa Finnigan MAT 262, do Laboratório de Geocronologia, do
Instituto de Geociências da Universidade de Brasília.

As incertezas para as razões ${ }^{147} \mathrm{Sm} /{ }^{144} \mathrm{Nd} \mathrm{e}{ }^{143} \mathrm{Nd} /{ }^{144} \mathrm{Nd}$ estão em torno de $+0,2 \%(2 \sigma)$ e $+0,005 \%(2 \sigma)$, respectivamente, baseadas em análises repetidas de padrões internacionais BHVO-1 e BCR-1. As razões ${ }^{143} \mathrm{Nd} /{ }^{144} \mathrm{Nd}$ foram normalizadas para ${ }^{143} \mathrm{Nd} /$ ${ }^{144} \mathrm{Nd}$ de 0,7219 e a constante de decaimento $(\sigma)$ usada foi de $6,54 \times 10^{-12}$.

\section{GEOLOGIA E PETROGRAFIA DAS ROCHAS RICAS EM TURMALINA}

Turmalinitos estratiformes Os corpos de turmalinitos afloram nas minas da Passagem, Mata Cavalo e Scliar como camadas negras de dimensão métrica, camadas centimétricos a milimétricos, e também na forma de brechas nos veios adjacentes; na maioria dos casos, ocorrem posicionados na base das formações ferríferas bandadas (Fig.3a). São corpos foliados e concordantes com as rochas encaixantes, sendo muitas vezes interrompidos por veios discordantes. Além da foliação principal $\left(\mathrm{S}_{\mathrm{n}}\right)$, exibem dobras assimétricas, clenulação e boudinage.

Os turmalinitos estratiformes são compostos principalmente por turmalina $(80-90 \%)$ e matéria carbonácea $(10-20 \%)$, e ainda contém como minerais acessórios quartzo, apatita, rutilo, titanita, zircão, pirita, arsenopirita e calcopirita (Fig.3b). A granulação é predominantemente fina e em raros casos é média. Os cristais de turmalina exibem textura nematoblástica com cristais prismáticos subidiomórficos e ocorrem distribuídos ao longo do plano da foliação principal e rotacionados sobre os flancos de microdobras. A matéria carbonácea, de granulação fina aparece principalmente na forma de inclusões e também nos contatos entre os cristais de turmalina formando aglomerados (nuvens) e estreitas camadas paralelas à foliação principal.

Quando mineralizados, a composição dos turmalinitos muda bruscamente, pois o mesmo passa a conter quartzo, carbonato, arsenopirita e muscovita. Pode conter até $25 \%$ em volume de arsenopirita; o conteúdo de matéria carbonácea reduz a menos de $5 \%$ e o quartzo aparece como produto das reações hidrotermais. As brechas de turmalinito possuem matriz de quartzo recristalizado, com textura granoblástica poligonal exibindo extinção ondulante, semelhante ao quartzo de veio.

A principal camada de turmalinito estratiforme mineralizado atinge até 3 metros de espessura, sendo interrompido em vários pontos por veios (Vqts) que cortam toda a seqüência litológica envolvida com a mineralização da Mina da Passagem. A lapa dessa camada de turmalinito é um sericita-quartzo xisto e a capa é um metachet que repousa sobre uma unidade carbonática, a qual, segundo Duarte (1991), constitui uma formação ferrífera carbonática composta principalmente por ankerita, Fe-dolomita e Mg-siderita. Brechas desse turmalinito são comumente encontradas nos veios adjacentes que, por sua vez, também constituem parte do minério.

Halos de turmalinização Os halos de turmalinização são bastante comuns na área estudada, ocorrendo ao longo de toda a seqüência litológica envolvida com a mineralização (Fig.3c). Foram descritos em todas as minas estudadas, aparecendo, geralmente, em associação com camadas ricas em sericita, biotita e carbonato das encaixantes, com espessuras muito variáveis e, em geral, exibindo feições de deformação como dobras abertas assimétricas. Localmente, podem ocorrer paralelos aos veios secantes e concordantes.

A composição mineralógica principal desses halos depende da composição das encaixantes. Nas rochas ricas em quartzo, os halos são compostos por turmalina, quartzo, matéria carbonácea e arsenopirita; nas rochas carbonáticas ocorrem quartzo, turmalina, carbonatos, matéria carbonácea, arsenopirita, pirita e rutilo; e nas rochas sericíticas são constituídos por sericita, quartzo e turmalina. Esses halos geralmente são foliados e apresentam 
bandamento composicional e dobras suaves (Fig.3d) A turmalina é de cor verde e granulação fina a média, os cristais geralmente são prismáticos idiomórficos e não exibem extinção ondulante.

Veios ricos em turmalina Os veios ricos em turmalina são do tipo quartzo-turmalina-sulfeto (Vqts) e quartzo-carbonatoturmalina-sulfeto (Vqcts), sendo que os veios de quartzo-carbonato-turmalina-sulfeto são anteriores aos veios de quartzoturmalina-sulfeto, ou seja, os veios de quartzo-carbonato-turmalina-sulfeto sempre são interceptados pelos veios de quartzo-turmalina-sulfeto, porém o contrário não ocorre. Os veios de quartzo-turmalina-sulfeto são geralmente subverticais, discordantes, mas possuem apófises concordantes com a foliação principal das encaixantes e constituem uma complexa estrutura arborescente que intercepta toda a seqüência litológica presente nas minas estudadas (Fig.3e). Associados às rochas carbonáticas estão os veios de quartzo-carbonato-turmalina-sulfeto que se posicionam concordantemente com a foliação principal das encaixantes.

Nos veios de quartzo-turmalina-sulfeto, que contêm agregados maciços de turmalina, também é comum a presença de brechas de turmalinito e de encaixantes. Já nos veios de quartzo-carbonato-turmalina-sulfeto, os agregados de turmalina aparecem na forma de filmes e a turmalinização em torno destes deu origem aos níveis de alteração concordante com a foliação principal das encaixantes, sendo esta situação muito comum nas rochas carbonáticas.

Nos veios, a turmalina aparece na forma de agregados maciços, brechas de turmalinito imersas na massa de quartzo de veio, e na forma de níveis nos veios bandados a quartzo-turmalina (Fig.3f). A turmalina é verde oliva, de granulação grossa, apresentando zoneamento irregular de cor sendo verde oliva nas bordas e verde claro no centro. Exibe textura granoblástica a nematoblástica e extinção ondulante.

\section{QUIIMICA MINERAL DAS TURMALINAS}

Apresentação dos dados As análises foram realizadas em turmalinas do turmalinito estratiforme (T1), dos halos de turmalinização (T2) e dos veios mineralizados (T3). De acordo com o esquema de classificação proposto por Hawthorne \& Henry (1999), considerando-se o principal componente no sítio X, todas as turmalinas da área estudada pertencem ao grupo das turmalinas alcalinas (Fig.4a), com exceção de quatro análises de turmalinas de veios que plotam no campo das turmalinas cálcicas. Neste gráfico, as turmalinas T1 formam um grupo isolado, enquanto as turmalinas T2 e T3 se sobrepõem parcialmente. Utilizando como critério as variações composicionais do grupo das turmalinas alcalinas, elas foram classificadas como dravita (Fig.4b).

Apesar de existirem variações nos conteúdos dos elementos maiores nas turmalinas em seus diferentes modos de ocorrência, as composições são muito semelhantes (Tabela 1). As variações mais importantes ocorrem nos conteúdos (\% em peso) de $\mathrm{MgO}$ $\left(6,03\right.$ - 9,75), $\mathrm{FeO}(3,45-7,80), \mathrm{Al}_{2} \mathrm{O}_{3}(30,83-34,30)$ e $\mathrm{CaO}$ $(0,07-1,56)$. No turmalinito estratiforme (T1), o conteúdo de $\mathrm{MgO}$ varia entre $(6,59$ - 9,75) e o de $\mathrm{FeO}$ entre $(3,45$ - 6,87); nos halos de turmalinização (T2) o $\mathrm{MgO}$ está entre $(6,03$ - 8,64) e o de $\mathrm{FeO}$ entre $(4,76-7,80)$; e nos veios (T3) o $\mathrm{MgO}$ assume valores entre $(6,89-8,10)$ e o $\mathrm{FeO}$ entre $(4,46-7,01)$.

$\mathrm{Na}$ figura $4 \mathrm{~b}$, observa-se que há sobreposição das turmalinas dos diferentes modos ocorrência, sejam elas pertencentes ao turmalinito, aos halos de turmalinização ou aos veios. As turmalinas dos halos de alteração e dos veios exibem um campo mais restrito envolvido pelo campo das turmalinas do turmalinito. Esta sobreposição pode ser explicada pela semelhança composicional que existe entre as mesmas e também pela geração das novas turmalinas (T2 e T3) durante o processo de mineralização

Apesar do grande número de substituições que ocorrem nos minerais do grupo da turmalina, diversos autores têm utilizado diagramas ternários para classificar a turmalina, considerando que as substituições mais importantes são de $\mathrm{Al}, \mathrm{Fe}, \mathrm{Mg}$ e Ca. No gráfico $\mathrm{Al}-\mathrm{Fe}_{(\text {tot) }}-\mathrm{Mg}$, as turmalinas foram plotadas de acordo com os modos de ocorrência (Fig.4c). Neste diagrama, as turmalinas do turmalinito estratiforme plotam no campo dos metapelitos e metapsamitos, que não coexistem com fases saturadas em Al. Porém parte delas plotam no campo de metapelitos e metapsamitos com fases saturadas em Al, o que pode estar relacionado às alterações hidrotermais que ocorreram no turmalinito devido ao metamorfismo e ao processo mineralizante que atuou na região. Já a maioria das análises das turmalinas dos halos de alteração hidrotermal e dos veios mineralizados plotam no campo de metapelitos e metapsamitos com fases saturadas em $\mathrm{Al}$, correspondendo às turmalinas que se formaram tardiamente devido ao metamorfismo e ao processo mineralizante.

No diagrama $\mathrm{Ca}-\mathrm{Fe}_{(\text {tot })}-\mathrm{Mg}$, todas as turmalinas plotam no campo dos metapelitos, metapsamitos e rochas de quartzo-turmalina pobres em Ca (Fig.4d). As composições das turmalinas pertencentes aos halos de alteração e aos veios praticamente se sobrepõem mais uma vez. A variação do conteúdo de $\mathrm{Mg}$ e Fe são mais amplas nas turmalinas T1, enquanto em T2 e T3 este conteúdo é mais restrito, o que pode estar relacionado com a origem primeira da turmalina $\mathrm{T} 1$.

GEOQUÍMICA DO Nd Foram selecionadas nove amostras de turmalinas, seguindo os mesmos critérios utilizados na química mineral, ou seja, turmalinas do turmalinito, dos halos de alteração e dos veios mineralizados (Tabela 2). Como foi visto anteriormente, os turmalinitos geralmente encontram-se deformados e/ou alterados hidrotermalmente. A amostra MS-03, da Mina Scliar, guarda estruturas primárias, ou seja, o turmalinito foi poupado da deformação. Esta amostra apresenta valores anômalos, quando correlacionados com outras, como é o caso das amostras das minas da Passagem, Mata Cavalo e Duas Bocas, que além de exibir estruturas de deformação, também foram alteradas hidrotermalmente e mineralizadas.

$\mathrm{O}$ diagrama $\mathrm{Sm}$ vs. $\mathrm{Nd}$ exibe uma correlação positiva entre os valores das turmalinas do turmalinito, dos halos de alteração e dos veios, e indica que não houve abertura do sistema (Fig. 5a). A razão ${ }^{143} \mathrm{Nd} /{ }^{144} \mathrm{Nd}$, nas turmalinas dos turmalinitos, exibe valores entre 0,510846 e 0,511119; nas turmalinas dos halos de alteração, estão entre 0,511034 e 0,511096 ; e nos veios entre 0,511029 e 0,511186 . A razão ${ }^{147} \mathrm{Sm} /{ }^{144} \mathrm{Nd}$, nas turmalinas dos turmalinitos, apresenta valores entre 0,0965 e 0,1225 ; na turmalina dos halos de alteração entre 0,1230 e 0,1332 ; e na dos veios entre 0,1341 e 0,1551 . O diagrama ${ }^{143} \mathrm{Nd} /{ }^{144} \mathrm{Nd}$ vs. ${ }^{147} \mathrm{Sm} /{ }^{144} \mathrm{Nd}$ não mostra uma boa correlação entre estes valores (Figura $5 b$ ). Já o $\varepsilon_{\mathrm{Nd}}(0)$ assume valores entre: -34,96 e -29,64 na turmalina do turmalinito; entre -32,06 e -30,09 nos halos de alteração; e valores entre $-31,38$ e -28,32 nos veios mineralizados. O diagrama relacionando a razão ${ }^{143} \mathrm{Nd} /{ }^{144} \mathrm{Nd}$ vs. $\varepsilon_{\mathrm{Nd}}(0)$ exibe correlação positiva entre esses valores (Fig. 5c).

DISCUSSÃO E INTERPRETAÇÃO DOS DADOS O estudo da composição química das turmalinas vem corroborar a hipótese de que os turmalinitos são de origem exalativo-sedimentar, pois, além de estar localizados na base de formações ferríferas bandadas, a turmalina dos turmalinitos pertence ao grupo alcalino, tendo sido classificada como dravita rica em $\mathrm{Mg}$, ou seja, com baixa razão $\mathrm{FeO} /(\mathrm{FeO}+\mathrm{MgO})$, principalmente no caso da Mina Scliar, onde registram-se valores entre 0,26 e 0,32. A razão $\mathrm{FeO} /(\mathrm{FeO}+\mathrm{MgO})$ aumenta em direção às turmalinas dos veios e halos de alteração. $\mathrm{O}$ enriquecimento em $\mathrm{Mg}$ 
pode ser interpretado como o produto de sistemas hidrotermais exalativos tipo Sedex, mas também pode ter origem relacionada à reação de fluidos hidrotermais magmáticos com rochas ricas em $\mathrm{Mg}$, como por exemplo, rochas metaultramáficas (Jiang et al. 1999). Mas o contexto geológico da mineralização aurífera e do turmalinito exclui esta última alternativa. O posicionamento estratigráfico do turmalinito está bem definido, encontrando-se na base das formações ferríferas bandadas, como visto anteriormente. As turmalinas dos halos e dos veios são mais ricas em $\mathrm{Al}($ tot) e Fe(tot) e podem ser o resultado de reações que ocorreram com a introdução do fluido hidrotermal que deu origem aos veios mineralizados e também aos halos de alteração hidrotermal nas rochas encaixantes (sericita-quartzo xisto, quartzo-sericita xisto, quartzito sericítico, filito cabonáceo e biotita xisto).

A evolução tectônica do Quadrilátero Ferrífero é marcada, principalmente, pelos dois eventos tectôno-metamórficos Transamazônico e Brasiliano. O evento Transamazônico possui duas fases bem marcadas: i) uma fase há $2,115 \mathrm{Ga}$, de natureza compressiva que gerou um cinturão de empurrão e dobramento; e outra fase há $2,095 \mathrm{Ga}$, de natureza extensional, que deu origem à arquitetura de "domos e quilhas", relacionada à colocação de domos sobre as rochas supracrustais e que teve como conseqü-
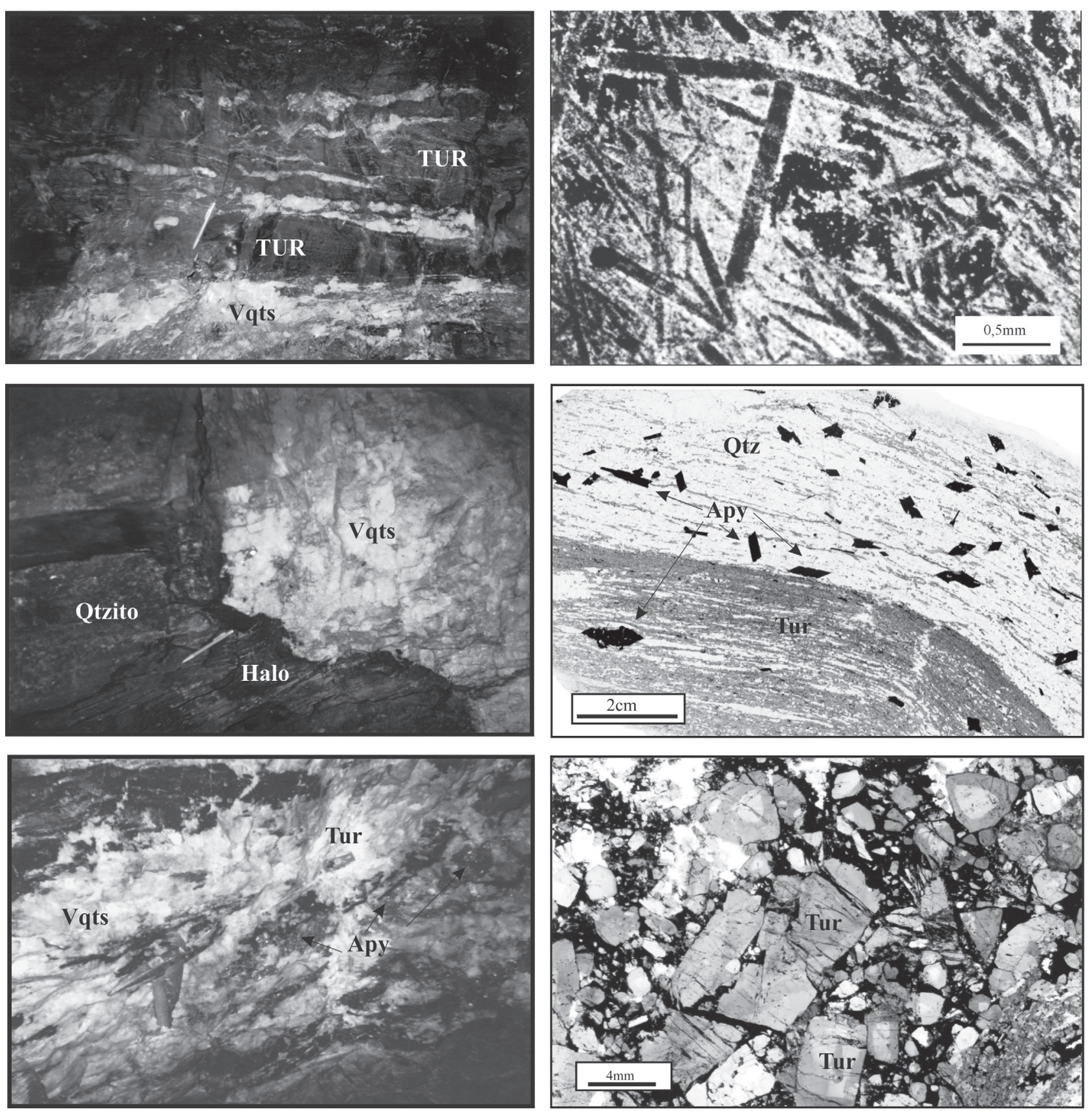

Figura 3 - a) Afloramento de turmalinito estratiforme mineralizado situado na base da formação ferrifera bandada. b) Fotomicrografia do turmalinito estratiforme composto por turmalina e matéria carbonácea. c) Foto do afloramento de um halo de turmalinização no quartzito sericítico(Qtzito) próximo à zona de contato com o veio de quartzo-turmalina-arsenopirita (Vqts). d) Foto da lâmina delgada-polida, exibindo halo de turmalinização no sericita-quartzo xisto da lapa do minério. O halo é bandado a turmalina (Tur) e quartzo(Qtz), sendo qua a banda rica em quartzo também o é em arsenopirita (Apy). e) Foto de afloramento de veio de quartzo-turmalina-arsenopirita (Vqts) contendo brechas de turmalinito. f) Fotomicrografia do aglomerado de turmalina (Tur) associado ao veio de quartzo-turmalina-arsenopirita. 


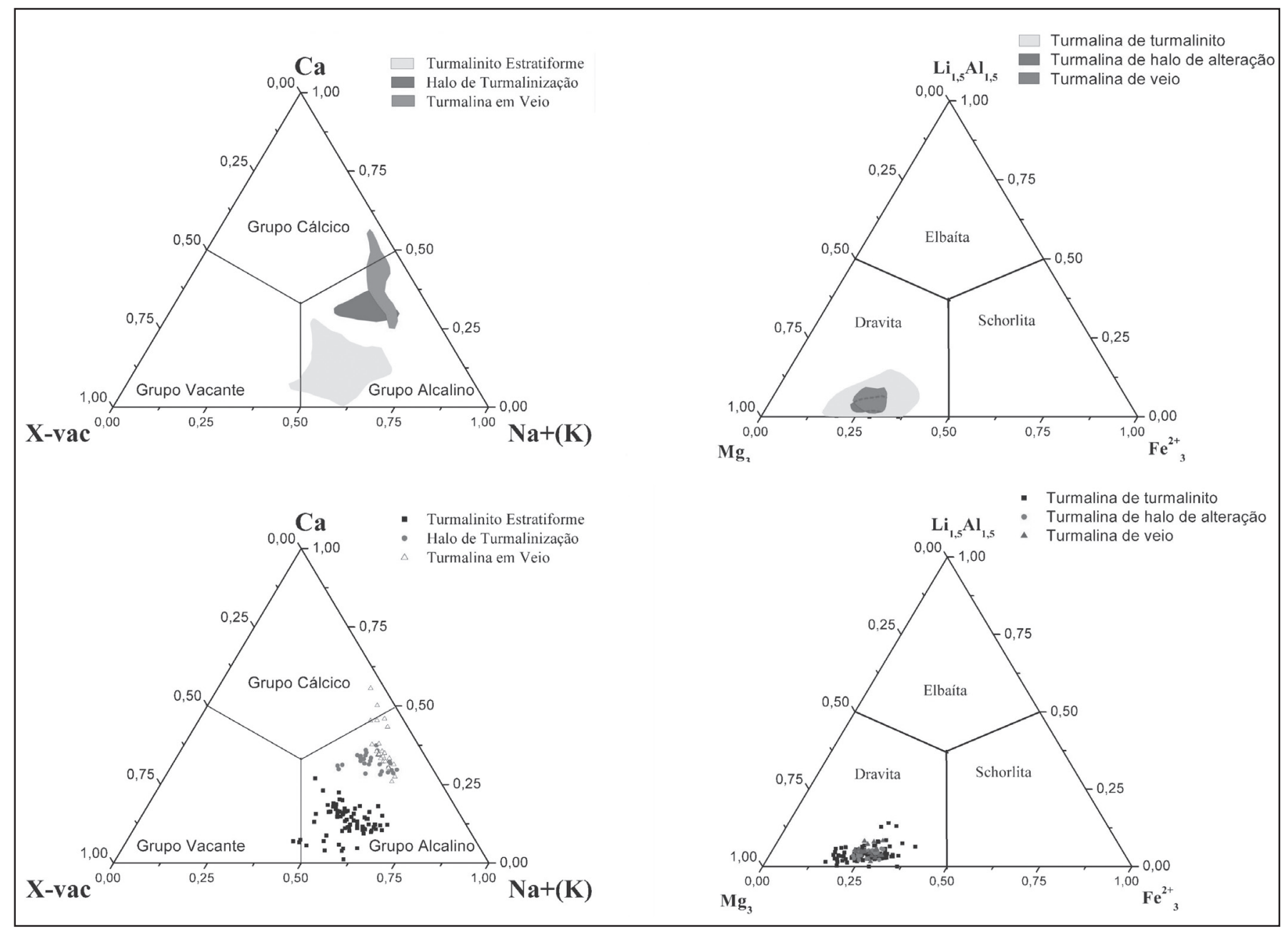

Figura 4 - a) Classificação dos minerais do grupo da turmalina, com base nos elementos que ocupam o sítio X. b) Classificação das tumalinas alcalinas (proposta por Hawthorne \& Henry 1999). Os cálculos das proporções moleculares foram realizados no programa Clastour (Yavuz et al. 2002). c) Classificação química usando o diagrama Al-Fe(tot)-Mg c 1) granitóides pegmatíticos ricos em Li; 2) granitóides e seus pegmatitos e aplitos associados pobres em Li; 3) metapelitos e metapsamitos que não coexistem com fases saturadas em Al; 4) metapelitos e metapsamitos coexistindo com fases saturadas em Al; 5) metaultramáficas com Cr e baixo Ca e metassedimentos ricos em V. d) Diagrama Ca-Fe(tot)-Mg de Henry \& Guidotti (1985): 1) granitóides pegmatíticos e aplíticos ricos em Li; 2) granitóides e seus pegmatitos e aplitos assosicados pobres em Li; 3) metapelitos, metapsamitos e rochas cálcio silicáticas ricas em $\mathrm{Ca}$; 4) metapelitos, metapsamitos e rochas de quartzo-turmalinas pobres em Ca; 5) Metacarbonatos; 6) metaultramáficas.

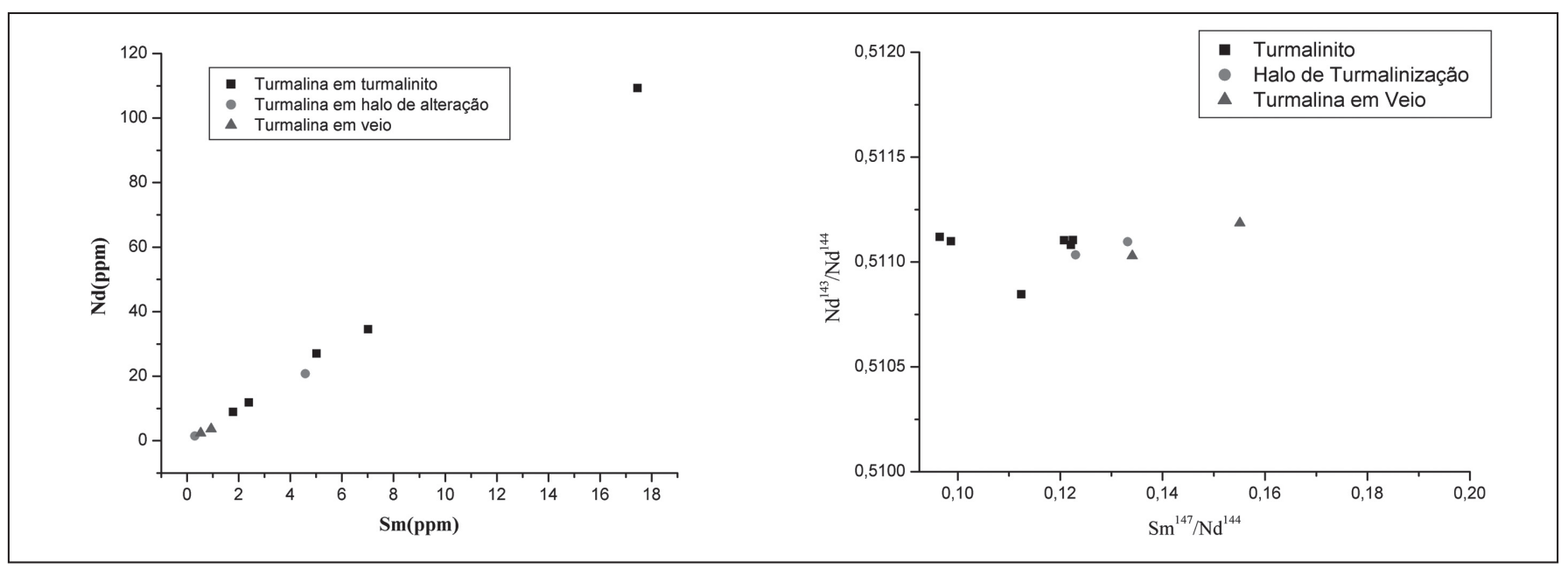

Figura 5 - a) Diagrama Sm vs. Nd; b) Diagrama ${ }^{143} \mathrm{Nd} /{ }^{144} \mathrm{Nd} v s .{ }^{147} \mathrm{Sm} / 144 \mathrm{Nd}$; e c) Diagrama ${ }^{143} \mathrm{Nd} /{ }^{144} \mathrm{Nd} v$ s. $\varepsilon_{\mathrm{Nd}}(0)$, para os três grupos de turmalinas. 
Tabela 1 - Composição química (\% peso) de turmalinas representativas dos três modos de ocorrência na área estudada: turmalinito (T1), halos de alteração (T2) e veios (T3).

\begin{tabular}{|c|c|c|c|c|c|c|c|c|c|}
\hline Amostras & 105 (T1) & 106 (T1) & 107 (T1) & 09 (T2) & $10(\mathrm{~T} 2)$ & 11 (T2) & 82 (T3) & 83 (T3) & 84 (T3) \\
\hline $\mathrm{SiO}_{2}$ & 36,94 & 37,37 & 36,92 & 35,86 & 35,33 & 35,94 & 36,56 & 37,32 & 36,36 \\
\hline $\mathrm{TiO}_{2}$ & 0,56 & 0,42 & 0,48 & 0,70 & 0,73 & 0,54 & 0,13 & 0,44 & 0,37 \\
\hline $\mathrm{Al}_{2} \mathrm{O}_{3}$ & 32,53 & 32,07 & 33,27 & 33,29 & 33,41 & 33,37 & 33,44 & 33,15 & 32,97 \\
\hline $\mathrm{Cr}_{2} \mathrm{O}_{3}$ & 0,06 & 0,15 & 0,06 & 0,19 & 0,18 & 0,21 & 0,08 & 0,06 & 0,02 \\
\hline MgO & 8,70 & 9,74 & 8,90 & 7,34 & 7,51 & 7,58 & 7,32 & 8,11 & 7,96 \\
\hline $\mathrm{CaO}$ & 0,81 & 0,61 & 0,66 & 0,99 & 1,02 & 0,86 & 0,21 & 0,62 & 0,55 \\
\hline MnO & 0,03 & 0,00 & 0,05 & 0,00 & 0,00 & 0,00 & 0,01 & 0,00 & 0,00 \\
\hline $\mathrm{FeO}$ & 4,14 & 3,45 & 3,53 & 5,63 & 5,60 & 5,43 & 5,03 & 4,45 & 4,63 \\
\hline $\mathrm{NiO}$ & 0,00 & 0,04 & 0,00 & 0,07 & 0,08 & 0,02 & 0,00 & 0,04 & 0,01 \\
\hline $\mathrm{Na}_{2} \mathrm{O}$ & 1,92 & 1,95 & 1,79 & 1,53 & 1,55 & 1,57 & 1,26 & 1,71 & 1,86 \\
\hline $\mathrm{K}_{2} \mathrm{O}$ & 0,00 & 0,00 & 0,02 & 0,00 & 0,02 & 0,01 & 0,03 & 0,02 & 0,00 \\
\hline $\mathbf{F}$ & 0,24 & 0,30 & 0,01 & 0,05 & 0,15 & 0,00 & 0,03 & 0,14 & 0,17 \\
\hline Cl & 0,00 & 0,00 & 0,03 & 0,01 & - & 0,02 & - & - & 0,00 \\
\hline Total & 85,93 & 86,10 & 85,72 & 85,66 & 85,58 & 85,55 & 84,10 & 86,06 & 84,90 \\
\hline \multicolumn{10}{|c|}{ Fórmula estrutural com base em 25,4 oxigênios. } \\
\hline & 105 (T1) & $106(\mathrm{~T} 1)$ & 107 (T1) & 09 (T2) & $10(\mathrm{~T} 2)$ & 11 (T2) & 82 (T3) & 83 (T3) & 84 (T3) \\
\hline $\mathbf{S i}$ & 5,99 & 6,00 & 5,94 & 5,90 & 5,91 & 5,86 & 6,00 & 6,00 & 5,96 \\
\hline Ti & 0,07 & 0,05 & 0,06 & 0,09 & 0,09 & 0,07 & 0,02 & 0,05 & 0,05 \\
\hline $\mathbf{A l}(\mathbf{T})$ & 0,01 & 0,00 & 0,06 & 0,10 & 0,09 & 0,14 & 0,00 & 0,00 & 0,04 \\
\hline $\mathbf{A l}(\mathrm{Z})$ & 6,00 & 6,00 & 6,00 & 6,00 & 6,00 & 6,00 & 6,00 & 6,00 & 6,00 \\
\hline $\mathbf{A l}(\mathbf{Y})$ & 0,21 & 0,10 & 0,26 & 0,26 & ,025 & 0,27 & 0,52 & 0,30 & 0,33 \\
\hline $\mathrm{Cr}$ & 0,01 & 0,02 & 0,01 & 0,02 & 0,02 & 0,03 & 0,01 & 0,01 & 0,00 \\
\hline Mg & 2,10 & 2,34 & 2,14 & 1,79 & 1,84 & 1,84 & 1,80 & 1,95 & 1,95 \\
\hline $\mathrm{Ca}$ & 0,14 & 0,11 & 0,11 & 0,17 & 0,18 & 0,15 & 0,04 & 0,11 & 0,10 \\
\hline Mn & 0,00 & 0,00 & 0,01 & 0,00 & 0,00 & 0,00 & 0,00 & 0,00 & 0,00 \\
\hline $\mathbf{F e}_{\text {(tot) }}$ & 0,56 & 0,47 & 0,48 & 0,77 & 0,77 & 0,74 & 0,70 & 0,60 & 0,64 \\
\hline $\mathbf{N i}$ & 0,00 & 0,01 & 0,00 & 0,01 & 0,01 & 0,00 & 0,00 & 0,01 & 0,00 \\
\hline $\mathbf{N a}$ & 0,60 & 0,61 & 0,56 & 0,49 & 0,49 & 0,50 & 0,53 & 0,54 & 0,59 \\
\hline $\mathbf{K}$ & 0,00 & 0,00 & 0,01 & 0,00 & 0,00 & 0,00 & 0,01 & 0,00 & 0,00 \\
\hline $\mathrm{Fe} /(\mathrm{Fe}+\mathrm{Mg})$ & 0,21 & 0,17 & 0,18 & 0,30 & 0,03 & 0,29 & 0,28 & 0,24 & 0,25 \\
\hline $\mathrm{Na} /(\mathrm{Na}+\mathrm{Ca})$ & 0,81 & 0,85 & 0,83 & 0,74 & 0,73 & 0,77 & 0,83 & 0,86 & 0,81 \\
\hline
\end{tabular}

Tabela 2 - Dados isotópicos de Sm-Nd de turmalina da região do Anticlinal de Mariana-MG.

\begin{tabular}{|c|c|c|c|c|c|c|}
\hline Tipo & Amostra & $\begin{array}{l}\text { Sm } \\
\text { ppm }\end{array}$ & $\begin{array}{l}\text { Nd } \\
\text { ppm }\end{array}$ & $\begin{array}{c}{ }^{147} \mathrm{Sm} /{ }^{144} \mathrm{Nd} \\
\text { medido }\end{array}$ & $\begin{array}{c}{ }^{143} \mathrm{Nd} /{ }^{144} \mathrm{Nd} \\
\text { medido }\end{array}$ & $\mathbf{e}_{\mathrm{Nd}}(\mathbf{0})$ \\
\hline $\mathrm{T} 1$ & PM22 & 1,782 & 8,920 & 0,1208 & 0,511103 & $-29,94$ \\
\hline $\mathrm{T} 1$ & MC-02 & 2,399 & 11,871 & 0,1221 & 0,511081 & $-30,37$ \\
\hline $\mathrm{T} 1$ & PM-16 & 7,011 & 34,588 & 0,1225 & 0,511104 & $-29,92$ \\
\hline $\mathrm{T} 1$ & MS-03 & 17,450 & 109,280 & 0,0965 & 0,511119 & $-29,63$ \\
\hline $\mathrm{T} 1$ & MDB-01 & 0,529 & 2,386 & 0,1341 & 0,511029 & $-31,39$ \\
\hline $\mathrm{T} 2$ & MCR-04 & 0,300 & 1,475 & 0,1230 & 0,511034 & $-31,29$ \\
\hline $\mathrm{T} 2$ & PM37 & 4,582 & 20,797 & 0,1332 & 0,511096 & $-30,08$ \\
\hline $\mathrm{T} 3$ & PM-23 & 0,935 & 3,644 & 0,1551 & 0,511186 & $-28,32$ \\
\hline $\mathrm{T} 3$ & MDB-N1 & 5,020 & 26,998 & 0,1124 & 0,510846 & $-34,96$ \\
\hline
\end{tabular}

ência o colapso orogênico (Alkmim \& Marshak, 1998).

A mineralização aurífera da região do Anticlinal de Mariana está relacionada à orogênese transamazônica, datada entre 2093 e 2067 Ma por Schrank \& Machado (1996), que corresponde à fase extensional de tal evento e que causou ascensão de núcleos metamórficos, associada aos aparelhos hidrodinâmicos responsáveis pela injeção de pegmatitos, alteração hidrotermal e colo- cação de corpos sulfetados auríferos. No flanco sul do Anticlinal de Mariana é comum a presença de boudinage da foliação em escala de dezenas a poucas centenas de metros (Naline, 1993, Oliveira 1998, Cavalcanti 1999). Nas minas estudadas, principalmente na Mina da Passagem, a principal estrutura relacionada à colocação dos veios mineralizados também é a boudinage da foliação principal. 
Aceitando-se como mais consistente a hipótese de que os turmalinitos estratiformes são singenéticos, os eventos tectonometamórficos que ocorreram posteriormente à sua formação geraram a foliação principal, a qual foi posteriormente dobrada, crenulada e rompida. Os filitos carbonosos e rochas sericíticas da sucessão estrtatigráfica estudada são anômalos em boro (Fleischer \& Routhier, 1973) e podem também ter contribuído com boro para a formação de turmalinas tardias durante os eventos metamórficos que afetaram a região.

Os valores das razões isotópicas de ${ }^{147} \mathrm{Sm} /{ }^{144} \mathrm{Nd}$ da turmalina são mais baixos do que o CHUR, indicando que houve um enriquecimento em ETR leves. As turmalinas T2 e T3 possuem razões ${ }^{147} \mathrm{Sm} /{ }^{144} \mathrm{Nd} \mathrm{e}{ }^{143} \mathrm{Nd} /{ }^{144} \mathrm{Nd}$ mais altas do que as turmalinas $\mathrm{T} 1$, indicando que ocorreram reações de fluidos hidrotermais com as encaixantes durante a formação das turmalinas T2 e T3.

Com relação ao turmalinito estratiforme, foram consideradas duas hipóteses:

a) O turmalinito estratiforme é singenético e ocorre na base das formações ferríferas bandadas do Grupo Itabira as quais tiveram sua sedimentação iniciada em 2,54 Ga (Babinsky et al 1995); que é considerada a idade mínima para o turmalinito estratiforme. Para o cálculo do $\mathrm{e}_{\mathrm{vg}}(\mathrm{T})$ foi utilizada a idade de 2,54 Ga e todos os valores de $\mathrm{e}_{\mathrm{Nd}}(2,54)$ são negativos, entre $-7,46 \mathrm{e}$ $-5,18$, com exceção do turmalinito da Mina Scliar, que apresentou valor positivo $(+3,13)$, mais próximo do CHUR (Tab. $3)$. Este turmalinito é aquele que possui estruturas primárias preservadas podendo representar um sistema "fossilizado", que

Tabela 3: Valores de $e_{N d}$ a formação das turmalinas na região do Anticlinal de Mariana. PM (Mina da Passagem), MC (Mina Mata Cavalo), MS (Mina Scliar), $2 B$ (Mina Duas Bocas).

\begin{tabular}{c|c|c|c|c}
\hline Amostra & Tipo & $\mathbf{e}_{\mathrm{Nd}}(\mathbf{2 , 5 4 )}$ & $\mathbf{e}_{\mathrm{Nd}} \mathbf{( 2 , 0 9 3 )}$ & Origem \\
\hline PM22 & $\mathrm{T} 1$ & $-5,18$ & & singenético \\
\hline MC-02 & $\mathrm{T} 1$ & $-5,72$ & & singenético \\
\hline PM-16 & $\mathrm{T} 1$ & $-6,04$ & & singenético \\
\hline MS-03 & $\mathrm{T} 1$ & 3,13 & & singenético \\
\hline 2B-01 & $\mathrm{T} 1$ & $-7,46$ & & singenético \\
\hline CR-04 & $\mathrm{T} 2$ & & $-13,08$ & $\begin{array}{c}\text { metamórfico- } \\
\text { hidrotermal }\end{array}$ \\
\hline PM37 & $\mathrm{T} 2$ & & $-11,54$ & $\begin{array}{c}\text { metamórfico- } \\
\text { hidrotermal }\end{array}$ \\
\hline PM-23 & $\mathrm{T} 3$ & & $-17,23$ & $\begin{array}{c}\text { metamórfico- } \\
\text { hidrotermal }\end{array}$ \\
\hline 2B-N1 & $\mathrm{T} 3$ & & $-14,68$ & $\begin{array}{c}\text { metamórfico- } \\
\text { hidrotermal }\end{array}$ \\
\hline & & & &
\end{tabular}

guarda características do ambiente de formação do turmalinito, ao contrário dos turmalinitos das outras minas, que foram intensamente deformados e alterados hidrotermalmente. $\mathrm{O}$ valor obtido na amostra da Mina Scliar pode indicar que o fluido que deu origem ao turmalinito era de fonte mista, tanto de origem profunda como também da pilha de sedimentos, sendo ele reponsável pelos focos exalativos de fluidos ricos em boro.

Os dados de campo, petrográficos, de química mineral e isotópicos indicam que o boro contido nas turmalinas do turmalinito, dos halos de alteração hidrotermal e dos veios pode ser da mesma fonte, apesar de as turmalinas terem se formado em diferentes momentos e de haver a participação de diferentes fontes de fluidos na formação das mesmas.

CONCLUSÃO Com base nos estudos realizados nas rochas ricas em turmalina na região do Anticlinal de Mariana, concluise que:

- A partir das relações de campo, foram distinguidos três modos de ocorrência da turmalina: i) turmalina em corpos estratiformes de turmalinito; ii) turmalina em halos resultantes da alteração hidrotermal das rochas encaixantes do minério; e iii) turmalina como componente dos veios mineralizados.

- Com relação à química, as turmalinas são todas alcalinas, classificadas como dravitas. No gráfico $\mathrm{Al}-\mathrm{Fe}_{(\text {tot }}-\mathrm{Mg}$, as turmalinas do turmalinito estratiforme plotaram no campo dos metapelitos e metapsamitos que não coexistem com fases saturadas em Al. Porém, mas parte dessas turmalinas plotaram no campo de metapelitos e metapsamitos com mineralogia saturada em $\mathrm{Al}$, o que pode estar relacionado às alterações hidrotermais que ocorreram no turmalinito devido ao metamorfismo e ao processo mineralizante que atuou na região. Já a maioria das turmalinas dos halos de alteração hidrotermal e as dos veios mineralizados plotaram no campo de metapelitos e metapsamitos com mineralogia saturada em $\mathrm{Al}$, que corresponde às turmalinas que se formaram tardiamente devido ao metamorfismo e ao processo mineralizante.

- Finalmente, foi avaliada a composição isotópica de Nd nas turmalinas. Os valores das razões isotópicas de $\mathrm{Sm} / \mathrm{Nd}$ são mais baixos do que o CHUR, indicando que há um enriquecimento em ETR leves. As turmalinas T2 eT3 possuem razões $\mathrm{Sm} / \mathrm{Nd}$ e $\mathrm{Nd} / \mathrm{Nd}$ mais altas do que as turmalinas $\mathrm{T} 1$, indicando que ocorreram reações de fluidos hidrotermais com as encaixantes durante a formação das turmalinas T2 eT3. Isto pode implicar que a fonte dos fluidos que geraram as turmalians T2 e T3 é diferente da que deu origem aos turmalinitos estratiformes.

A correlação entre os dados de campo, petrografia, química mineral e os isótopos de $\mathrm{Nd}$ indicou que: i) a circulação profunda de fluidos gerou focos exalativos ricos em boro, que resultaram na precipitação do turmalinito estratiforme; ii) a formação da turmalina dos halos de turmalinização e dos veios mineralizados está relacionada com a mistura de fluidos mobilizados das rochas encaixantes e daqueles provenientes do sistema mineralizante.

\section{Referências}

Alkmim F.F. \& Marshak S. 1998. Transamazonian orogeny in the southern São Francisco Craton region, Minas Gerais, Brazil: evidence for Paleoproterozoic collision and collapse in the Quadrilátero Ferrífero. Precambrian Research, 90:29-58.

Almeida F.F.M. de. 1977. O cráton São Francisco. Revista Brasileira de Geociências, 7:349-364.

Almeida F.F.M. de. 1981. O cráton Paramirim e suas relações com o do São Francisco. In: Núcleo Bahia-Sergipe/SBG, Simpósio sobre o Cráton São Francisco e suas Faixas Marginais, Salvador Anais, p.1-10.

Babinski M., Chemale Jr. F., Van Schmus W.R. 1995. The Pb/Pb age of the Minas Supergroup carbonate rocks, Quadrilátero Ferrífero, Minas Gerais, Brazil. Precambrian Research, 72:235-245.

Barbosa A.L.M. 1969. Geologic map of Ouro Preto, Mariana, Antônio Pereira e São Bartolomeu quadrangles, Minas Gerais, Brazil. U.S. Geological Survey, Profissional Paper, 641-A, Plates 7, 8, 9, 10.

Barbosa A.L.M., Dorr J.V.N., Sad J.H.G. 1974. The consanguineous origin of the tourmaline bearing gold deposit: Passagem de Mariana (Brazil). Economic Geology, 69:416-418.

Black P.M. 1971. Tourmalines form Cuvier Island, New Zealand. Mineralogical Magazine, 38:374-376. 
Bone Y. 1998. The geological setting of tourmalinite at Rum Jungle, N.T., Australia - genetic and economic implications. Mineralium Deposita, 23:34-41.

Byerly G.R. \& Palmer M.R. 1991. Tourmaline mineralization in the Barberton Greenstone Belt, South Africa: early Archean metasomatism by evaporite-derived boron Contribuitions to Mineralogy and Petro$\log y$, 107:387-402.

Cavalcanti J.A.D. 1999. Mineralização aurífera de Lages-Antônio Dias, Ouro Preto MG: controles lito-estratigráficos e estruturais. Dissertação de Mestrado, Instituto de Geociências, Universidade Estadual de Campinas, Campinas, 108p.

Cavalcanti J.A.D. \& Shrank A. 1999. Controles litoestratigráficos dos turmalinitos auríferos na região de Ouro Preto, Quadrilátero FerríferoMG. Revista da Escola de Minas, 52(2):100-108.

Cavarretta G. \& Puxeddu M. 1990. Schorl-Dravite-Ferridravite tourmalines deposited by hydrothermal magmatic fluids during early evolution of the Larderelo Geothermal Field, Italy. Economic Geology, 85:12361251.

Chauvet A., Dussin I.I., Faure M., Charvet J. 1994. A three-stage structural evolution of the Quadrilatero Ferrifero: consequenses for the Neoproterozoic age and the formation of gold concentrations of the Ouro Preto area, Minas Gerais, Brazil. Pre-Cambrian Research, 68:139-167.

Chauvet A., Piantone P., Barbanson L., Nehlig P., Pedroletti I. 2001. Gold deposit during collapse tectonics: structural, mineralogical, geochronological, and fluid inclusion constraints in Ouro Preto gold mines, Quadrilátero Ferrífero, Brazil. Economic Geology, 96:25-48.

Clarke D.B., Reardon N.C., Chatterjee A.K., Gregoire D.C. 1989. Tourmaline composition as a guide to mineral exploration: A reconnaissance study from Nova Scotia using discriminant function analysis. Economic Geology, 84:1921-1935.

Cleland J.M., Morey G.B., McSwiggen L. 1996. Significance of tourmaline-rich rocks in the north Range Group of the Cuyuna Iron Range, east-central Minnesota. Economic Geology, 91:1282-1291.

DePaolo D.J., 1951. Neodymium isotope geochemistry: an introduction. Springer, Berlin, 187p.

Dommanget A., Milési J.P., Diallo M. 1993. The Loulo gold and tourmaline-bearing deposit: a polymorph type in the Early Proterozoic of Mali (west Africa). Mineralium Deposita, 28:253-263.

Duarte B.P. 1991. Contribuição ao estudo da geologia do corpo de minério fundão do depósito aurífero de Passagem de Mariana, Mariana$M G$. Dissertação de Mestrado, Instituto de Geociências, Universidade Federal do Rio de Janeiro, Rio de Janeiro, 175p.

Endo I. 1997. Regimes tectônicos do Arqueano e Proterozóico no interior da Placa Sanfranciscana: Quadrilátero Ferrifero e áreas adjacentes, Minas Gerais. Tese de Doutoramento, Instituto de Geociências, Universidade de São Paulo, S. Paulo, 243p.

Endo I. \& Machado R. 2002. Reavaliação e novos dados geocronológicos $(\mathrm{Pb} / \mathrm{Pb}$ e K/Ar) da região do Quadrilátero Ferrífero e adjacências. Geologia USP Série Cientifica, 2:23-40.

Ethier V.G. \& Campbell F.A. 1977. Tourmaline concentrations in Proterozoic sediments of the southern Cordillera of Canada and their significance. Canadian Journal of Earth Sciences, 14:2348-2363.

Fleischer R. \& Routhier P. 1973. The "consanguineous" origin of a tourmaline-bearing gold deposit: Passagem de Mariana (Brazil). Economic Geology, 68:11-22.

Foster R.P. \& Piper D.P. 1993. Archean lode gold deposit in Africa: crustal setting, metallogenesis and cratonization. Ore Geology Reviews, 8:303-347.

Garba I. 1996. Tourmalinization related to Late Proterozoic-Early Paleozoic lode gold mineralization in the Bin Yauri area, Nigeria. Mineralium Deposita, 31:201-209.

Gioia S.M.C.L. \& Pimentel M.M. 2000. The Sm-Nd isotopic method in the geochronology laboratory of the University of Brasília. Anais $d a$ Academia Brasileira de Ciências, 72(2):219-245.

Griffin W.L., Slack J.F. 1996. Trace elements in tourmalines from massive sulfide deposits and tourmalinites: geochemical controls and exploration applications. Economic Geology, 91(4):657-675.

Groves D.I., Barley M.E., Ho S.E. 1989. Nature, genesis and tectonic sitting of mesothermal gold mineralization in the Yilgarn Block, western Australia. In: R.R. Keays, W.R.H. Ransay, D.I. Groves (eds) The geology gold deposits: the perspective in 1988. Econ. Geol. monogr. 6, p. $71-85$.
Harraz H.Z. \& El-Sharkawy M.F. 2001. Origin of tourmaline in the metamorphosed Sikait politic belt, south Eastern Desert, Egypt. Journal of African Earth Sciences, 33:391-416.

Hawthorne F.C. \& Henry D.J. 1999. Classification of the tourmaline group. European Journal of Mineralogy, 11: 201-215.

Heineck C.A., Ribeiro J.H., Francescato J.A., Silva E.S. 1986. As mineralizações auríferas de Mata Cavalo, Minas da Passagem, Mariana, MG. In: SBG, Congresso Brasileiro de Geologia, 34, Goiânia, Anais, v. 5, p. 1932-1937.

Henry D.J. \& Dutrow B.L. 1998. Metamorphic tourmaline and its petrographic applications. In: L.M. Anovitz \& E.S. Grew (eds.) Boron: mineralogy, petrography and geochemistry. Reviews in Mineralogy, v. 33, p. 503-543.

Henry D.J. \& Guidotti C.V. 1985. Tourmaline as a petrogenetic indicator mineral: an example from the staurolite-grade metapelites of NW Maine. American Mineralogist,70:1-15.

Jébrak M., Mineau R., Bardoux M., Goulet N. 1990. Boron cycle in the Abitibi Greenstone Belt, and compositional variations in tourmaline associated with gold deposit (abst). In: F. Robert, P.A. Sheahan, S.B. Green (eds). Greenstone Gold and Crustal Evolution. NUNA Conf. Vol., Geol. Assoc. Canada, p. 177.

Jiang S.Y., Palmer M.R., Xue C.J. 1995. Chemical compositions of tourmaline in the Yindongzi-Tongmugou Pb-Zn deposits. Qinling, China: implications for hydrothermal ore-forming processes. Mineralium Deposita, 30:225-234.

Jiang S.Y., Palmer M.R., Yeats C.J. 2002. Chemical and boron isotopic compositions of tourmaline from the Archean Big Bell and Mount Gibson gold deposits, Murchison Province, Yilgarn Craton, Western Australia. Chemical Geology, 188:229-247.

Jiang S.Y., Han F., Shen J.Z., Palmer M.R. 1999. Chemical and Rb-Sr, SmNd isotopic systematics of tourmaline from the Dachang Snpolymetallic ore deposit, Guangxi Province, P.R. China. Chemical Geology, 157:49-67.

Kretz R., Hartree R., Jones P. 1989. Metassomatic crystallization of muscovite in granite and tourmaline in schist related to pegmatite emplacement near Yellowknife, Canada. Contribuitions to Mineralogy and Petrology, 102:191-204.

Ladeira E.A. 1991. Genesis of gold in Quadrilátero Ferrífero: a remarkable case of permanency, recycling and inheritance - a tribute to Djalma Guimarães, Pierre Routhier and Hans Ramberg. In: E.A. Ladeira (ed.), Brazil Gold'91. Belo Horizonte, Balkema, 11-30.

Lanari C. 1977. A mineração do ouro. In: SICEG/Sociedade de Intercâmbio Cultural e Estudos Geológicos, Semana de Estudos, Simpósio sobre o ouro, 17, Ouro Preto-MG, Atas, p. 21-52.

Leeman W.P., Sisson V.B., Reid M.R. 1992. Boron geochemistry of the lower crust: evidence od granulite terranes and deep crustal xenoliths. Geochimica et Cosmochimica Acta, 56:775-788.

Lerouge C., Miléce J.P., Fouillac A.M. 1999. The Paleoproterozoic gold deposit, French Guiana: genetic constraints of the stable isotope geochemistry. Chemical Geology, 155:131-149.

London D. \& Manning D.A.C. 1995. Chemical variation and significance of tourmaline from southwest England. Economic Geology, 90:495519.

London D., Morgan G.B.V.I., Wolf M.B. 1996. Boron in granitic rocks and their content aureoles. In: E.S. Grew \& L.M. Anovitz (eds.) Boron: mineralogy, petrology and geochemistry. Reviews in Mineralogy, v.33, p. 299-330.

Naline Jr. H.A. 1993. Análise estrutural descritiva e cinemática do flanco sul e terminação piriclinal do Anticlinal de Mariana e adjacências, região sudeste do Quadrilátero Ferrífero, $M G$, Brasil. Dissertação de Mestrado, Instituto de Geociências, Universidade Federal de Minas Gerais, Belo Horizonte, 132p.

Oliveira F.R. 1998. Contribuição ao estudo da geologia estrutural e da gênese do depósito aurífero de Passagem de Mariana-MG. Dissertação de Mestrado, Instituto de Geociências, Universidade Estadual de Campinas, Campinas, 126p.

Palmer M.R. \& Slack J.F. 1989. Boron isotopic composition of tourmaline from massive sulfide deposits and tourmalinites. Contributions to Mineralogy and Petrology, 103(4): 434-451.

Pesquera A. \& Velasco F. 1997. Mineralogy, geochemistry and geological significance of tourmaline-rich rocks from the Paleozoic Cinco Villas massif (western Pyrenees, Spain). Contribuition to Mineralogy and 
Petrology, 129:53-74.

Plimer I.R. 1986. Tourmalinites from the Golden Dyke Dome, Northern Australia. Mineral. Deposita, 21:263-270.

Potts P.J., Bowles J.F.W., Reed S.J.B. \& Cave M.R. 1995. Microprobe Techniques in the Earth Sciences. Chapman \& Hall, 419 p.

Schrank A. \& Machado N. 1996. Idades em monazitas e zircões das minas de Morro Velho e Passagem de Mariana - Quadrilátero Ferrífero (MG). In: SBG, Congresso Brasileiro de Geologia, 39, Recife, Anais, v. 6 , p. $470-472$.

Shearer C.K., Papike J.J., Simon S.B., Laul J.C., Christian R.P. 1984. Pegmatite/wall rocks interations, Black Hills, South Dakota: progressive boron metassomatism adjacent to the Tip Top pegmatite. Gechemica et Cosmochimica Acta, 48:2563-2579.

Silva L.C. 1991. A preliminary evaluation of the Brazilian Archean and Proterozoic strabound tourmalinites and their significance as potential gold deposit. In: E.A. Ladeira (ed.) Brazil Gold'91. Rotterdan, Balkema, p. 241-245.

Siva Siddaiah N. \& Rajamani V. 1989. The geologic sitting, mineralogy, geochemistry and genesis of gold deposit of the Archean Kolar Schist belt, India. Economic Geology, 84:2155-2172.

Slack J.F. 1996. Tourmaline associations with hydrothermal ore deposits. In: E.S. Grow \& L.M. Anovitz (Eds.) Boron mineralogy, petrology and geochesmistry. Reviews in Mineralogy, v. 33, p. 560-643.

Slack J.F., Herriman N., Barnes R.G., Plimer I.R. 1984. Stratiform tourmalinites in metamorphic terranes and their geologic significance.
Geology, 12:713-716.

Slack J.F., Palmer M.R., Stevens B.P.J., Barnes R.G. 1993. Originand significance of tourmaline-rich rocks in the Broken Hill District, Australia. Economic Geology, 88(3): 505-541.

Steven N.M. \& Moore J.M. 1995. Tourmalinite mineralization in the Late Proterozoic Kuiseb Formation of the Damara Orogen, central Namibia: evidence of replacement origin. Economic Geology, 90:10981117.

Taylor B.E. \& Slack J.F. 1984. Tourmalines from Appalachian-Caledonian massive sulfide deposit: textural, chemical and isotopic relationships. Economic Geology, 79: 1703-1726.

Torres-Ruiz J., Pesquera A., Gil-Crespo P. P., Velilla N. 2003. Origin and petrogenetic implication of tourmaline-rich rocks in the Sierra Nevada (Betic Cordillera, southeastern Spain). Chemical Geology, 197:5586.

Vial D.S. 1988. Mina de ouro de Passagem de Mariana, Minas Gerais. In: C. Schobbenhaus \& C.E.S. Coelho (Eds.) Principais Depósitos Minerais do Brasil. Brasília, DNPM, v. 3, p. 421-430.

Yavuz F., Gültekin A.H., Karakaya M.C. 2002. Clastour: a computer program for classification of the minerals of the tourmaline group. Computers \& Geoscience, 28:1017-1036.

Manuscrito A1648

Aprovado em 6 de outubro de 2006 